\title{
Contributors to Success on the Automotive Service Excellence (ASE) Student Certification Exam
}

\author{
Robert K. Vlacich ${ }^{\mathrm{a}}$, Mark D. Threeton ${ }^{\mathrm{b}}$, Kyungin Kim ${ }^{\mathrm{b}}$ \\ ${ }^{a}$ Pennsylvania College of Technology, ${ }^{b}$ Pennsylvania State University
}

\begin{abstract}
This study sought to identify which elements contribute to success on the Automotive Service Excellence (ASE) Student Certification exam. Students at an eastern U.S. technical college who completed all of their automotive major courses and the ASE Student Certification exam during the spring 2017 semester were selected for the study. The results of this study revealed that there was a direct correlation between performance in Physics, Algebra, and Trigonometry 1 and performance on the ASE Student Certification exam. It was also revealed that students who were required to participate in remedial math and/or remedial reading courses were likely to perform at a lower level than their counterparts on the exam. Students who participated in a secondary automotive Career and Technical Education (CTE) program were also likely to perform at a lower level than their counterparts. The results of this study would be useful to administrators and faculty in postsecondary automotive preparation programs.
\end{abstract}

Keywords: Automotive Service Excellence (ASE), standardized testing

\section{Introduction}

Technological advancements over the years have brought a major transformation to the automotive industry. Automobiles today play a significant role in shaping the culture, economy, and the day-to-day lives of Americans. As automobiles have become more complex and highly technical, so have the educational requirements of an automotive technician. In fact, technicians today need to develop academic and technical skills in order to adequately respond to the demands of the automotive industry (Lundquist, 2000).

Untrained individuals can no longer repair modern automobiles because of the drivability systems and onboard computers that are currently utilized to control critical systems. A traditional approach of on-the-job training will not prepare an individual for the current level of complexity within the automotive field today and could result in many costly mistakes which businesses cannot afford (Duffy, 2014). As such, Duffy (2014) emphasized the need for adequate training in order to be successful as an automotive technician.

In order to be properly prepared and competitive in this field, an automotive technician needs to acquire extensive professional development. Technical training 
programs are one of the best ways for students to prepare for entry-level positions in automotive service technology. These programs typically run for six months to two years, helping students' career preparation through hands-on learning as well as academic instruction (Occupational Outlook Handbook, 2016). Since employers are expecting entry-level employees to have a proper academic background in this field, secondary and postsecondary automotive preparation programs are in place to provide a career pathway for individuals to obtain this type of education (Lundquist, 2000). Having a standardized set of parameters that automotive technology programs must follow is imperative. To meet this need, the National Automotive Technicians Education Foundation (NATEF), a division of Automotive Service Excellence (ASE), serves as an accrediting agency for training programs at high schools and postsecondary institutions. Their focus is to provide accreditation for automotive service technology training programs. The NATEF establishes the standards for automotive technology programs and has accredited programs that teach the skills automotive technicians should learn (National Automotive Technicians Education Foundation, 2016).

The ASE Student Certification Exam. Upon completion of a NATEF-accredited program, students are given the opportunity to take the ASE Student Certification exam. This exam serves as an entry-level certification pathway, which was established to evaluate the achievement of automotive service (National Institute for Automotive Service Excellence, 2019). This assessment is similar to the professional ASE exams, except that it is based on the knowledge, skills, and dispositions that students have developed while actively enrolled in a NATEF-accredited program.

The subject areas covered in the program and on the exam include: (a) Automatic Transmission/Transaxle; (b) Brakes; (c) Electrical/Electronic Systems; (d) Engine Performance; (e) Engine Repair; (f) Heating and A/C; (g) Maintenance and Light Repair; (h) Manual Drivetrain and Axles; and (i) Suspension and Steering. If a student successfully passes the exam, the school awards them with a certificate signed by the supervising administrator (National Institute for Automotive Service Excellence, 2019).

This exam serves as a capstone activity for the learner, which when passed is a respected credential within the automotive industry. The collective results of the student exams can be extremely useful to faculty members in detecting, analyzing, and correcting educational deficiencies in NATEF-accredited programs. However, at this time there is no research available on what variables contribute to success on the ASE student exams. This phenomenon creates a problem that requires further investigation.

Factors Related to Student Performance on Certification Exams. With no published literature examining the contributors to success on the ASE Student Certification exam, the primary investigator was forced to widen the boundaries of the search to include related framing literature on the predictors of success on other examinations and educational settings. This was unavoidable given the absence of related literature on this topic. However, it should be noted that reviewing literature on a related and extended topic is a recommended practice that professional scholars often utilize in 
situations where there is a dearth of directly related literature on the issues to be investigated (Pautasso, 2013).

In the past, researchers have tried to identify what predictors of success exist for students taking exams. For example, MacMillan and Fujita (2005) studied students who completed dental assisting degrees to determine what variables predict student success on the Dental Assisting National Board (DANB) exam. This study examined two variables: students' GPA in a dental assisting program and mock board exam scores. The results of this study revealed that both variables were a significant predictor of success on the DANB exam. McKinney, Small, O’Dell, and Coonrod (1988) researched students who completed a baccalaureate degree in nursing and took the National Council Licensing Examination (NCLEX). The researchers determined that pre-entrance test scores, GPA, Mosby Assessment Test scores, and courses repeated were statistically significant factors for NCLEX success.

Peng, Le, and Milburn (2011) investigated students who completed a business or technical degree at a Canadian college. They discovered that math placement scores and participation in remedial math courses were correlated to a student's GPA. They determined that students who performed poorly in math are more likely to have a lower final overall GPA. Leopold and Edgar (2008) revealed that math performance was directly correlated with success in chemistry. This provided evidence that math performance can be a predictor of success in other college courses beyond just mathematics. Finally, Montague and Hays (2008) conducted a study to predict student success in college biology. This study revealed that verbal SAT scores and high school GPA were significant factors which contributed to success.

Research has also been conducted to determine what factors predict success in college as a whole. For example, Belfield and Crosta (2012) revealed that placement tests are not very effective in determining how well a student will perform in college. They did; however, determine that high school GPA is correlated with college GPA and college credit accumulation. The results of this research suggested that academic predictors vary from course to course and program to program. Therefore, there appears not to be a single predictor of college success.

\section{Purpose}

The purpose of this study was to explore what essential elements contribute to success on the ASE Student Certification exam. Four variables were selected for this study based on the review of related literature: performance in major-specific courses, placement exam scores, work experience, and preadmission experiences. Research on the impact of these variables could be useful in helping automotive preparation programs determine what contributes to a student's success on the exam. Therefore, this study sought to answer the following research questions:

1. What was the distribution of students' scores on the ASE Student Certification exam?

2. What correlation exists between student major specific course grades and performance on the ASE Student Certification exam? 
Journal of Research in Technical Careers

3. What correlation exists between required student remedial courses as determined by the college placement exam and performance on the ASE Student Certification exam?

4. What correlation exists between student work experience and performance on the ASE Student Certification exam?

5. What correlation exists between student preadmission experience (participation in secondary CTE classes, family history of automotive technicians, etc.) and performance on the ASE Student Certification exam?

\section{Theoretical Framework}

Upon completion of a NATEF-accredited automotive program, students are expected to have excellent communication skills, exemplary mechanical aptitude and manual dexterity, the ability to analyze, problem solve, and follow directions with great accuracy (National Automotive Technicians Education Foundation, 2016). It is the expectation that students should develop this knowledge, skill, and ability through experiences provided throughout the educational program. This type of experiential learning, as Smith (2001) indicated, is the "sort of learning undertaken by students who are given a chance to acquire and apply knowledge, skills and feelings in an immediate and relevant setting" (p. 1). In this case, the relevant setting is within automotive technology and these skill sets are assessed on the ASE Student Certification exam in the context of automotive service and repair tasks and simulations.

The theoretical foundation of this study was grounded within Kolb's Experiential Learning Theory (ELT) (1984), given that NATEF-accredited automotive programs and related assessments provide integrated classroom instruction with laboratory experiences to provide students with enhanced opportunities to learn. Experiential learning has gained popularity in education over the years. Kolb's experiential learning foundation draws on the work of Dewey, emphasizing the importance of experiences in the learning process (Rudowski, 1996). It is grounded in the theoretical framework of personal experience (Ausburn \& Brown, 2006). Kolb’s ELT was established on six propositions:

(a) Learning is best conceived as a process, not in terms of outcomes. To improve learning in higher education, the primary focus should be on engaging students in a process that best enhances their learning a process that includes feedback on the effectiveness of their learning efforts. (b) All learning is relearning. Learning is best facilitated by a process that draws out the students' beliefs and ideas about a topic so that they can be examined, tested, and integrated with new, more refined ideas. (c) Learning requires the resolution of conflicts between dialectically opposed modes of adaptation to the world. Conflict, differences, and disagreement are what drive the learning process. In the process of learning one is called upon to move back and forth between opposing modes of reflection and action and feeling and thinking. (d) Learning is a holistic process of adaptation to the world and not just the result of cognition. Learning involves the integrated functioning of the total person thinking, feeling, perceiving, and behaving. (e) Learning results from synergetic transactions between 


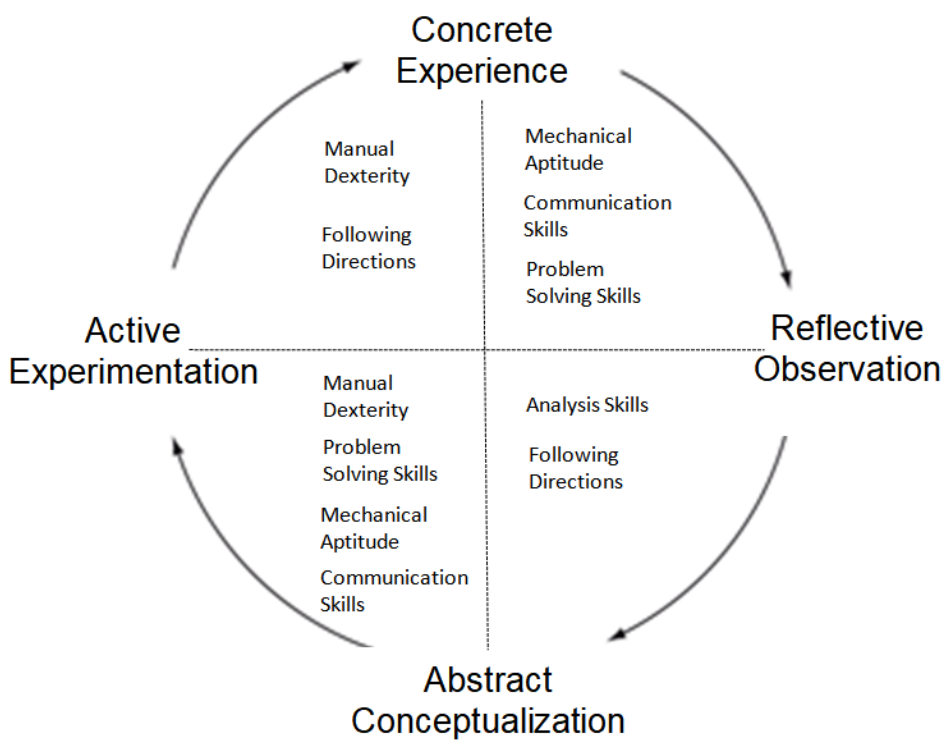

Figure 1. Knowledge, skill, and ability of a NATEF program completer (Kolb, 1984)

the person and the environment. (f) Learning is the process of creating knowledge. (Kolb \& Kolb, 2005, p. 194).

Kolb's ELT (1984) identifies four modes of grasping experience: concrete experience, reflective observation, abstract conceptualization, and active experimentation. Kolb and Fry (1975) revealed that the experiential learning process can begin for students at any one of the four modes, but should be regarded as a continuous cycle which can promote enhanced learning and skill development. This continuous educational cycle serves as a foundation for NATEF-accredited automotive programs. Automotive faculty utilize experiential learning practices in the classroom and laboratory to promote success on the ASE student exams and to advance the transfer of learning to the world of work. Figure 1 illustrates this connection in context.

\section{Method}

Target Population. The target population of this study included postsecondary students at an eastern U.S. technical college. At the time when the study was conducted, this Middle-States-accredited higher education institution had more than 5,000 enrolled students pursuing either a professional certificate or an undergraduate degree in one of more than 100 different available majors. Subjects specifically eligible to participate in this study were required to meet each of the following criteria: (a) associate-degreeseeking students currently enrolled in a career preparation program in the automotive technology field [i.e., Automotive Technology, Ford Automotive Student Service 
Table 1. Participant Age as of May 1, $2017(n=56)$

\begin{tabular}{lllllll}
\hline Age & 19 & 20 & 21 & 22 & 23 & 24 \\
\hline Frequency & 10 & 29 & 9 & 4 & 0 & 4 \\
Percentage & 17.9 & 51.8 & 16.1 & 7.10 & 0.0 & 7.2 \\
\hline
\end{tabular}

Table 2. Participant Gender ( $n=56$ )

\begin{tabular}{lll}
\hline Gender & Male & Female \\
\hline Frequency & 55 & 1 \\
Percentage & 98.2 & 1.8 \\
\hline
\end{tabular}

Table 3. Student Program ( $n=56)$

\begin{tabular}{lllll}
\hline Program & Automotive & Honda PACT & MOPAR CAP & Ford ASSET \\
\hline Number & 41 & 4 & 6 & 5 \\
Percent & 73.2 & 7.2 & 10.7 & 8.9 \\
\hline
\end{tabular}

Note. None of the 56 students were enrolled in the Automotive Technician Certificate Program.

Educational Training (ASSET), Honda Professional Automotive Career Training (PACT), and Mopar Career Automotive Program (CAP)]; (b) students who had completed all of their automotive major classes; (c) students who completed the ASE Student Certification exam during the spring 2017 semester; and (d) students who were 18 years of age or older. According to the designated technical college enrollment records for spring 2017, 57 students met the criteria to participate in the study and all were invited to participate.

Background of Participants. The age of participants ranged from 19 to 24 years (Table 1). A majority (98.2\%) of the participants were male students and were actively enrolled in the general automotive technology program (Tables 2 \& 3).

Instrumentation. A survey research method was used to conduct the study. A questionnaire was developed to assess the preadmission experience of the participants, including: (a) prior work experience, cooperative education experience, internship experience, work experience outside of the educational setting, experience as a secondary CTE program student, and family history of automotive technicians. Prior to launching the study, the questionnaire was reviewed by a panel of subject matter experts (SMEs) for face and content validity. The SMEs were well versed in automotive technology, career and technical education, and survey development. After the panel completed the analysis, the primary investigator amended the questionnaire to correspond with the prescribed recommendations of correcting minor grammatical errors and removing redundant items.

Data Collection. The data collection phase of this research study was conducted at one eastern U.S. technical college. Appropriate clearance was obtained from the Research 
Protections Office regarding the inclusion of human subjects in this research study. Both primary and secondary data were utilized within this investigation. Primary data were obtained by use of the aforementioned questionnaire. Secondary data were collected from two different sources. The first source was a student database at the designated technical college, which housed information relating to placement exams ${ }^{1}$ (required remedial courses), course grades ${ }^{2}$ [For example, specifically for Physics Survey and Technical Algebra and Trigonometry 1], and demographics. The second source of secondary data were the results of the ASE Student Certification exam. This data was provided the school from ASE.

Upon launching the study, the primary investigator visited each of the second-year classes in-person and administered the questionnaire no more than one week prior to when the ASE Student Certification exam was conducted. During this time, the purpose of the study was explained to the participants and written consent was obtained from each individual. No questionnaires were completed on the day of the exam. This was done to prevent lackluster completion of the questionnaire due to potential test anxiety regarding the ASE Student Certification exam. Of the 57 students that met the eligibility criteria, 56 chose to participate (i.e., 98.2\% response rate). Since only one person did not participate, the data were treated as a census for the purpose of this study, and therefore $p$ values were not reported.

Data Analysis. Data were manually entered into a Microsoft Excel spreadsheet and coded. The spreadsheet was then transferred into IBM SPSS Statistics software. A Pearson product-moment correlation and Spearman's rank correlation were calculated to determine the best predictors of success on the ASE Student Certification exam. Correlations are discussed and reported as follows: Little or no relationship 0 to \pm .25 , Fair relationship \pm .26 to \pm .50 , Moderate to good relationship \pm .51 to \pm .75 , Very good to excellent relationship \pm .76 to \pm 1.00 (Fink, 1995). Means and frequencies for the demographics were also calculated.

\footnotetext{
${ }^{1}$ As part of the enrollment process at this institution, students are required to take a placement exam. The purpose of the exam is to ensure that students are prepared for college level work. Those who are not properly prepared are either required to take developmental coursework or are not accepted into the school. The developmental coursework is designed to further one's skills in order to meet the standard required to be successful at the institution.

${ }^{2}$ Physics Survey: General selection of physics topics, including matter and measurement; behavior of solids, liquids, and gases; mechanics, including forces, motion, energy, power, and machines; heat; sound; light; optics; magnetism; electricity; and atomic phenomena. Technical Algebra and Trigonometry I: Study of intermediate algebra and trigonometry, designed to prepare students for course work in their technical majors. Topics include algebraic expressions, linear equations, systems of equations, right triangle trigonometry, functions, graphs, geometry, ratio and proportion, and variation.
} 
Table 4. ASE Student Certification Exam Scores

\begin{tabular}{lcccc}
\hline Exam & Mean & Low & High & SD \\
\hline Suspension and Steering & 71.45 & 38 & 95 & 13.63 \\
& & & & \\
Brakes & 72.59 & 35 & 95 & 14.31 \\
Electrical/Electronic Systems & 74.63 & 35 & 95 & 14.55 \\
Engine Performance & 71.20 & 30 & 92 & 14.51 \\
Engine Repair & 81.80 & 55 & 98 & 9.90 \\
Automatic Transmission/Transaxle & 69.55 & 38 & 92 & 13.02 \\
Manual Drivetrain and Axles & 70.39 & 32 & 90 & 13.41 \\
Heating and A/C & 74.55 & 18 & 92 & 14.58 \\
Maintenance and Light Repair & 75.93 & 28 & 92 & 11.78 \\
\hline lote. Scres based & & & &
\end{tabular}

Note. Scores based upon a possible 100.

\section{Findings}

Research Question One. Research question one sought to identify the distribution of students' scores on the ASE Student Certification exam. Table 4 is provided to highlight the performance of participants on this assessment during the spring of 2017. This exam assessed students in nine categories based on the knowledge, skills, and dispositions they developed while actively enrolled in this NATEF-accredited program.

Research Question Two. Research question two sought to answer what correlation exists between student major specific course grades and performance on the ASE Student Certification exam. A Pearson product-moment correlation was calculated between student course grades and the ASE Student Certification exam scores. There were many significant strong correlations between automotive courses and certification exams in the same area. For example, it was found that a student who performed well in Suspension and Steering class was likely to also perform well on the Suspension and Steering ASE Student Certification exam. Due to the numerous expected correlations, these data were omitted from the study given that this was not the focus of the research. However, correlations were determined for two non-automotive courses, i.e., Physics Survey and Technical Algebra and Trigonometry 1. 
Table 7. Students Requiring Remedial Reading Courses $(n=56)$

\begin{tabular}{lll}
\hline Number of Courses & Frequency & Percent \\
\hline None & 48 & 85.7 \\
One Course & 8 & 14.3 \\
\hline
\end{tabular}

Table 8. Summary of Correlations between ASE Student Certification exams and Remedial Courses

\begin{tabular}{lll}
\hline Exam & Reading & Math \\
\hline Suspension and Steering & -.270 & -.510 \\
Brakes & -.251 & -.329 \\
Electrical/Electronic Systems & -.269 & -.294 \\
Engine Performance & -.300 & -.450 \\
Engine Repair & -.491 & -.369 \\
Automatic Transmission/Transaxle & -.520 & -.381 \\
Manual Drivetrain and Axles & -.407 & -.271 \\
Heating and A/C & -.379 & -.194 \\
Maintenance and Light Repair & -.277 & -.335 \\
\hline
\end{tabular}

Of the nine dependent variables, three had a moderate relationship with performance in Physics Survey: Electrical/Electronic Systems (.629), Engine Performance (.514), and Engine Repair (.561). Five other dependent variables had a fair degree of relationship with Physics Survey; Suspension and Steering (.445), Brakes (.333), Automatic Transmission/Transaxle (.465), Heating and Air Conditioning (.301), and Maintenance and Light Repair (.447). It should be noted that eight of the nine dependent variables had a fair to good correlation to Physics Survey grades (Table 6).

Of the nine dependent variables, three had a moderate relationship with Technical Algebra and Trigonometry 1: Suspension and Steering (.505), Electrical/Electronic Systems (.569), and Engine Performance (.544). Four other dependent variables had a fair degree of relationship with Physics Survey; Brakes (.338), Engine Repair (.380), Automatic Transmission/Transaxle (.477), and Maintenance and Light Repair (.343). It should be noted that seven of the nine dependent variables had a fair to good correlation to Technical Algebra and Trigonometry 1grades (Table 5).

In response to question two, the results appear to reveal many correlations between student major specific course grades (i.e., automotive technology classes as well as other core classes required in the associate degree program) and performance on the ASE Student Certification exam. Most notable are the correlations for the Physics Survey and Technical Algebra and Trigonometry 1 courses. These correlations indicated a positive relationship between performance in these courses and the ASE Student Certification exam.

Research Question Three. Research question three sought to answer what correlation exists between required student remedial courses as determined by the college 
placement exam and performance on the ASE Student Certification exam. Of the 56 students in this study, 22 required one remedial course in mathematics while nine required two remedial mathematics courses as determined by the college placement examination (see table 6). This equals $55.4 \%$ of students requiring some level of remedial math. Only eight of the students required a remedial course in reading (Table 7).

A Pearson product-moment correlation was calculated to determine correlations between required remedial courses and ASE Student Certification exam grades. All nine independent variables had a fair negative correlation with required remedial reading except for the Automatic Transmission/Transaxle exam (-.520), which had a moderate negative correlation. The required number of remedial math classes $(0,1$, or 2$)$, when compared to the independent variables resulted in all negative correlations, the strongest of which was the Suspension and Steering exam (-.510). A summary of these data can be found in Table 8.

In response to question three, the results appear to reveal many negative correlations between the number of required student remedial courses and performance on the ASE Student Certification exam. These results indicated that students whom were required to complete a remedial math and/or remedial reading course were more likely to perform unfavorably on the ASE Student Certification exam.

Research Question Four. Research question four sought to answer what correlation exists between student work experience and performance on the ASE Student Certification exam. The Spearman correlation was calculated to answer this research question. A fair correlation was found between months of automotive related work experience and the following dependent variables; Automatic Transmission/Transaxle (.479), Manual Drivetrain and Axles (.298), and Maintenance and Light Repair (.280). There were no significant correlations between non-automotive work experience and performance on the ASE Student Certification exam. There was also no significant correlation between participation in an automotive internship and performance on the ASE Student Certification exam.

In response to question four, the results appear to reveal a connection between automotive related work experience and three of the tests on the ASE Student Certification exam. (Automatic Transmission/Transaxle, Manual Drivetrain and Axles, and Maintenance and Light Repair). It also appears there is no connection between nonautomotive work experience or participation in an automotive internship and performance on the ASE Student Certification exam.

Research Question Five. Research question five sought to answer what correlation exists between student preadmission experience (participation in CTE classes, family history of automotive technicians, etc.) and performance on the ASE Student Certification exam. A point biserial correlation was calculated to determine correlations between student participation in a secondary automotive program and ASE Student Certification exam grades (Table 9). A fair negative correlation was discovered between student participation in a high school automotive program and the following two 
Table 9. Summary of Correlations between ASE Student Certification exams and Participation in a Secondary Automotive Program

\begin{tabular}{lc}
\hline Exam & Participation in CTE Program \\
\hline Suspension and Steering & -.110 \\
Brakes & -.058 \\
Electrical/Electronic Systems & -.348 \\
Engine Performance & -.244 \\
Engine Repair & -.154 \\
Automatic Transmission/Transaxle & -.105 \\
Manual Drivetrain and Axles & -.267 \\
Heating and A/C & -.076 \\
Maintenance and Light Repair & -.119 \\
\hline
\end{tabular}

Note. Data coded as follows: yes $=1$, no $=0$.

dependent variables; Electrical/Electronic Systems (-.348) and Manual Drivetrain and Axles (-.267).

There was no significant correlation between exam results and whether or not a student had either a parent or close relative who works or had worked as an automotive technician. While there was no correlation here, family history in the field may have had an impact on selecting the career path of an automotive technician. However, this is purely anecdotal and would require further investigation to make this determination. A Likert-type item on the questionnaire asked participants to respond to the statement, "As a child, I would often repair mechanical things such as bicycles, vacuum cleaners, lawn mowers, etc." There was no direct correlation between exam results and response to the statement. However, 42.9\% strongly agreed and 32.1\% agreed with the statement. Collectively, $75 \%$ of participants either agreed or strongly agreed with the statement.

In response to question five, the results appear to reveal a negative correlation between participation in an automotive CTE program and performance on the ASE Student Certification exam. (Table 9). The other independent variables were not found to be significant.

\section{Conclusions and Discussion}

This study explored what factors contribute to success on the ASE Student Certification exam. In response to question two, the results appear to reveal many correlations between student major specific course grades and performance on the ASE Student Certification exam. It was of no surprise that there were many correlations between automotive courses and performance on the ASE Student Certification exam. One of the most notable items was that there was a correlation found between two nonautomotive courses, Physics Survey and Technical Algebra and Trigonometry 1. These correlations indicated a positive relationship between performance in these courses and the ASE Student Certification exam. These results are congruent with research performed 
by Peng, Le, and Milburn (2011) who determined that students who perform poorly in math are more likely to have a lower final overall GPA. It is unclear whether it is the content of these courses or some other factors as to why there is such a correlation. While physics and math are both integrated within automotive technology, it is possible there are other contributing factors. Perhaps there are similarities in the thought process required to be successful in these courses that are also effective in the automotive courses, or perhaps the problem-solving skills in these courses are similar to the diagnostic skills required of automotive technicians. Another potential explanation might simply be that some students are better at taking written exams than others and therefore may perform better on such tests than their counterparts.

In response to question three, the results appear to reveal many negative correlations between the number of required student remedial courses and performance on the ASE Student Certification exam. These results indicated that students who are required to complete remedial math and/or remedial reading courses are more likely to perform unfavorably on the ASE Student Certification exam. These results solidify the need for foundational academics in the automotive trade.

In response to question four, the results appear to reveal a connection between automotive related work experience and three of the tests on the ASE Student Certification exam (Automatic Transmission/Transaxle, Manual Drivetrain and Axles, and Maintenance and Light Repair). Somewhat surprising is the lack of connection between non-automotive work experience and the ASE Student Certification exam. The researcher anticipated that there would be a connection since having work experience may indicate a stronger work ethic that could transfer to the educational setting. Even more surprising was the lack of correlation between participation in an automotive internship and performance on the ASE Student Certification exam. One might expect participation in an internship would have a strong impact on exam performance since the skills learned in the educational setting are reinforced at the workplace. However, this was not the case in this study. Nor was it the case in a study by Middlemas, Manning, Gazzillo, and Young (2001) who found no correlation between the number of student clinical hours and performance on the National Athletic Trainers Association Board of Certification exam.

In response to question five, the results appear to reveal a negative correlation between participation in a secondary automotive CTE program and performance on the ASE Student Certification exam. This is somewhat surprising since students that have participated in an automotive CTE program have already been exposed to some of the curriculum prior to entering the program at the college level. Despite this exposure, these students did not perform as well as their counterparts who had not participated in a secondary automotive CTE program. This is not to say that the CTE programs at the secondary have had a negative impact on the students. However, it could have something to do with the overall academic preparedness of CTE students. The other independent variables were not found to be significant. 


\section{Implications and Recommendations}

Implications for Education. Students should be encouraged to work in the automotive industry while attending the program if at all possible. Part-time or summer employment could provide useful experience that helps make the connection between the concepts taught in the educational setting and the industry. This employment should be related to the automotive field in order to have such an impact on student professional development. This structure will also provide opportunities to develop in the automotive field in the context of Kolb's Experiential Learning Cycle (1984) including the modes of concrete experience, reflective observations, abstract conceptualizations, and active experimentation.

Students required to take remedial courses were less likely to perform well on the ASE Student Certification exam. This is something that is out of the hands of the college, but needs to be addressed in earlier grade levels. It is concerning when over half of the students arrive at college deficient in mathematics. How is a student in this situation expected to succeed? Students that have successfully graduated from high school should be better prepared for college-level entrance exams. Therefore, further research should be conducted to determine why students are unprepared to be successful in this program.

Implications for the Field. Employers should make every attempt to hire the most qualified and best-suited employees they can. There is no one measure that can predict or determine which candidate would be the best possible choice. A person's performance on a certification exam, albeit important, should not be the sole criteria considered. A person's work ethic, work experience, and desire to succeed should also be considered. It should be noted that the exam is computer-based with no tactile portion. While this is an easy way to administer exams, it is not necessarily the most accurate method to determine the overall preparedness of a student. Some students may be competent in the skills needed to be successful in the automotive industry, but just don't test well in such a setting. Thus, a hands-on portion added to the exam could possibly provide a more accurate assessment. The National Occupational Competency Testing Institute (NOCTI) conducts assessments in this manner, with a written and performance portion (NOCTI, 2017). A written and performance assessment would provide a more authentic assessment for students.

Recommendations for Future Research. The results of this study have brought about recommendations for future research. Since participants were solely from one eastern U.S. technical college; the findings are only applicable to that institution. Therefore, it is recommended that this study be replicated on a larger scale in order for the results to be generalizable. Further research should be conducted to determine what the connection is between both Physics Survey and Technical Algebra and Trigonometry 1 and the ASE Student Certification exam. This research could seek to determine whether it is the content of these courses or some other factors that contribute to this correlation.

It is also recommended that research should be conducted to determine if performance on the exam has any correlation to employment success. It would be 
interesting to see if performance on the exam has any correlation to obtaining and maintaining successful employment over an extended period of time. Professional compensation as a result of performance on the ASE Student Certification exam could also be explored.

\section{Limitations}

There are several limitations of this research. First, this study only examined 56 students from one technical college in the U.S. Therefore, the results are not generalizable beyond the target population. Second, the instrumentation utilized in this study was self-reporting in nature and the results could have been inadvertently misreported by participants. Third, there was a dearth of related literature on this specific research topic, which forced the researchers to widen the boundaries of the search to include related framing literature in diverse educational settings. This limited the ability of the investigators to compare and contrast parallel studies on this topic. With these limitations in mind, this research should be viewed as an empirical study that explores the elements that contribute to student success on the ASE Student Certification exam and promotes practical strategies and recommendations for the future of automotive technician preparation.

\section{References}

Ausburn, L. J., \& Brown, D. (2006). Learning strategy patterns and instructional preferences of career and technical education students. Journal of Industrial Teacher Education, 43(4), 6-38.

Belfield, C. R., \& Crosta, P. M. (2012). Predicting Success in College: The Importance of Placement Tests and High School Transcripts. CCRC Working Paper No. 42. Community College Research Center, Columbia University.

Duffy, J. E. (2014). Modern automotive technology. Tinley Park: Goodheart-Willcox

Fink, A. (1995). How to analyze survey data. Thousand Oaks: Sage Publications.

Kolb, A. Y., \& Kolb, D. A. (2005). Learning styles and learning spaces: Enhancing experiential learning in higher education. Academy of Management Learning \& Education, 4(2), 192-212.

Kolb, D. A. (1984). Experiential learning: Experience as the source of learning and development. Englewood cliffs, NJ: Prentice hall.

Kolb, D. A., \& Fry, R. (1975). Toward an applied theory of experiential learning. In C. Cooper (Ed.), Theories of group process. London: Wiley.

Leopold, D. G., \& Edgar, B. (2008, May). Degree of mathematics fluency and success in secondsemester introductory chemistry. Journal of Chemical Education, 85(5), 724-731. https://doi.org/10.1021/ed085p724

Lundquist, P. A. (2000, January). Get your automotive program nationally certified! Tech Directions, 59(6), 14-16.

MacMillan, B., \& Fujita, F. (2005). Predictors of success on the dental assisting national board exam. Dental Assistant, 74(2), 22-24.

McKinney, J., Small, S., O'Dell, N., \& Coonrod, B. A. (1988). Identification of predictors of success for the NCLEX and students at risk for NCLEX failure in a baccalaureate nursing program. Journal of Professional Nursing, 4(1), 55-59. 
Middlemas, D. A., Manning, J. M., Gazzillo, L. M., \& Young, J. (2001). Predicting performance on the national athletic trainers' association board of certification examination from grade point average and number of clinical hours. Journal of Athletic Training, 36(2), 136-140.

Montague, J. R., \& Hays, E. T. (2008). Predicting student success in a first-semester college biology course. Florida Scientist, 71(2), 105-114.

National Automotive Technicians Education Foundation. (2016). Retrieved June 12, 2016, from http://www.natef.org

National Institute for Automotive Service Excellence. (2016). ASE student certification. Retrieved October 21, 2016, from http://www.asestudentcertification.com

National Institute for Automotive Service Excellence. (2019). Entry-level certification program. Retrieved from http://www.ase.com/Entry-Level/

National Occupational Competency Testing Institute. (2017). Retrieved September 14, 2017, from http://www.nocti.org

Occupational Outlook Handbook, 2016-17 edition. (n.d.). Bureau of labor and statistics. Retrieved June 7, 2016, from http://www.bls.gov/ooh

Pautasso, M. (2013). Ten simple rules for writing a literature review. PLoS Computational Biology, 9(7), 1-4. https://doi.org/10.1371/journal.pcbi.1003149

Peng, X., Le, T., \& Milburn, R. K. (2011). Predicting a student's success at a post-secondary institution. Journal of Applied Research in the Community College, 19(1), 42-49.

Rudowski, R. M. (1996). Kolb's learning theory and the relationship of learning style preferences and teaching style preferences of extension educators. University Park, PA: The Pennsylvania State University.

Smith, M. K. (2001). David A. Kolb on experiential learning. Encyclopedia of Informal Education, 1-15. Retrieved from http://www.infed.org/b-explrn.htm 